\title{
Targeting long non-coding RNAs (IncRNAs) with oligonucleotides in cancer therapy
}

\section{Mark R. Pickard ${ }^{1}$ and Gwyn T Williams ${ }^{2}$}

${ }^{1}$ Chester Centre for Stress Research, Institute of Medicine, Bache Hall, University of Chester, Chester $\mathrm{CH} 2$ 1BR, UK.

\author{
${ }^{2}$ Apoptosis Research Group, School of Life Sciences, Huxley Building, Keele University, Keele ST5 \\ $5 B G$, UK.
}

Correspondence to: MR Pickard, Institute of Medicine, Bache Hall, University of Chester, Chester $\mathrm{CH} 2$ 1BR, UK. Email m.pickard@chester.ac.uk, or GT Williams, Apoptosis Research Group, School of Life Sciences, Huxley Building, Keele University, Keele ST5 5BG, UK. Email g.t.williams@keele.ac.uk Response to Commentaries on Pickard MR, Williams GT. The hormone response element mimic sequence of GAS5 IncRNA is sufficient to induce apoptosis in breast cancer cells. Oncotarget 2016;7;10104-16.

The Commentaries on our recent paper in Oncotarget (1), reporting the successful induction of apoptosis by a 23-base oligonucleotide mimicking a key section of IncRNA GAS5, have raised some important points and have further developed the broader application of IncRNA-targeting oligonucleotides in cancer therapy. This area is now attracting considerable attention, reflecting the rapidly growing awareness of the importance of IncRNAs in human cell biology and biomedicine the numbers of citations of IncRNA papers are currently doubling every year (2), and this is recognised in all three Commentaries $(3-5)$.

Fayda and Gezer (3) have emphasised the importance of such attempts to improve the therapy of breast cancer, in particular the therapy of triple-negative breast cancer, a particularly malignant and chemotherapy resistant form of the disease (6). They refer to one of the most important results of the original Oncotarget paper (1), i.e. that the 23-base oligonucleotide induced apoptosis in a triplenegative breast cancer line as well as in other breast-cancer lines. It is therefore particularly important to explore entirely novel opportunities, such as those presented by the emerging study of the IncRNAs, to produce and develop better treatments for clinically challenging cancers.

Both Fayda and Gezer (3) and Kino and Marr (4) rightly highlight the importance of future work on the IncRNA concerned, GAS5, to identify the steroid hormone receptor involved in the induction of apoptosis both by full-length GAS5 and by the 23-base oligonucleotide mimic. GAS5 does not interact with the oestrogen receptor (7), so its functional effects must be due to interaction with another, as yet unidentified, steroid hormone pathway.

Kino and Marr (4) provide further information on GAS5, i.e. that it is a host gene for small nucleolar RNAs (snoRNAs) $(8,9)$, and go on to discuss in some detail a key remaining question - how to improve the properties of oligonucleotides, such as the GAS5 hormone response element mimic (1), for practical clinical application. One particularly encouraging factor is that the obstacles to successful clinical use for the GAS5 hormone response element mimic are broadly the same as those faced by other oligonucleotide therapies, and these are being addressed enthusiastically by many 
laboratories because of the immense potential of highly specific therapies targeting a range of RNAs. The three Commentaries recognise that the Oncotarget paper (1) helps to provide proof-of-principle for the use of oligonucleotides targeting IncRNAs, and so may be adapted for other IncRNA classes, such as those involved in the control of transcription (e.g. in epigenetic mechanisms), RNA processing and cell signaling pathways (reviewed by Morris and Mattick (10)). Since most of the genome encodes IncRNAs (in contrast to the $2 \%$ or so that encodes protein-coding RNAs), we can deduce that the number of possible targets for improved cancer therapies is likely to be very large and the broad exploitation of this approach may prove very productive.

\section{Acknowledgements}

This work was supported by Breast Cancer Now, Prostate Cancer UK and Bloodwise.

\section{Footnote}

Conflicts of Interest: The authors have no conflicts of interest to declare.

\section{References}

1. Pickard MR, Williams GT. The hormone response element mimic sequence of GAS5 IncRNA is sufficient to induce apoptosis in breast cancer cells. Oncotarget 2016;7:10104-16.

2. Web of Science, http://wok.mimas.ac.uk/

3. Fayda M, Gezer U. GAS5 oligonucleotides as therapeutic agents in breast cancer. Translational Cancer Research 2016; in press

4. Kino T, Marr AK. A lovely leap toward the development of breast cancer therapy with long noncoding RNAs. Translational Cancer Research 2016; in press

5. Williams GT, Pickard MR. Long non-coding RNAs: new opportunities and old challenges in cancer therapy. Translational Cancer Research 2016; in press

6. Meseure D, Drak Alsibai K, Nicolas A, Bieche I, Morillon A. Long noncoding RNAs as new architects in cancer epigenetics, prognostic biomarkers, and potential therapeutic targets. BioMed Research International 2015;2015:320214.

7. Kino T, Hurt DE, Ichijo T, Nader N, Chrousos GP. Noncoding RNA Gas5 is a growth arrest- and starvation-associated repressor of the glucocorticoid receptor. Science Signaling 2010;3(107):ra8.

8. Smith CM, Steitz JA. Classification of gas5 as a multi-small-nucleolar-RNA (snoRNA) host gene and a member of the 5 '-terminal oligopyrimidine gene family reveals common features of snoRNA host genes. Mol Cell Biol 1998;18:6897-6909.

9. Williams GT, Farzaneh F. Are snoRNAs and snoRNA host genes new players in cancer? Nature Reviews Cancer 2012;12:84-88.

10. Morris KV, Mattick JS. The rise of regulatory RNA. Nature Reviews Genetics 2014;15:423-437. 